\title{
Разработка электродов электрохимических конденсаторов на основе кремний-углеродных структур
}

\author{
М. Григорьев ${ }^{1}$, Т. Михайлова ${ }^{2}$ Т. Мясоедова, к. т.н ${ }^{3}$
}

УДК 621.355 | ВАК 05.27.01

\begin{abstract}
Сегодня в мире быстрыми темпами увеличивается количество портативных электронных устройств, повышается вклад электротранспорта в общий грузопоток, развивается альтернативная энергетика. Это стимулирует спрос на мощные эффективные устройства накопления и хранения электрической энергии, в качестве которых можно использовать электрохимические конденсаторы. В этой области интенсивно ведутся исследования, направленные на улучшение характеристик, повышение технологичности этих компонентов. Авторы статьи предложили способ формирования электродов электрохимических конденсаторов на основе кремний-углеродных пленок путем электрохимического осаждения из раствора органических соединений. Исследования полученных экспериментальных образцов показали перспективность этого метода.
\end{abstract}

лектрохимические конденсаторы в ближайшем будущем могут частично заменить аккумуляторы или эффективно использоваться в тандеме, что уже происходит в некоторых устройствах [1]. По плотности энергии электрохимические конденсаторы постепенно приближаются к значениям аккумуляторов, а по таким параметрам, как пиковая мощность и скорость заряда-разряда, значительно превосходят последние. Высокую значимость электрохимических конденсаторов подтверждает стабильный рост их производства 20-25\% в год [2].

Электрохимические конденсаторы (ионисторы, суперконденсаторы) - это устройства, накапливающие энергию за счет емкости двойного электрического слоя и окислительно-восстановительных реакций на границе раздела

АО «Таганрогский научно-

исследовательский институт связи",

ведущий инженер-технолог,

gregoryevmikhail@mail.ru.

Южный федеральный университет,

кафедра техносферной

безопасности ихимии, аспирант,

xelga.maks@yandex.ru.

Южный федеральный университет,

кафедра техносферной

безопасности ихимии, доцент,

ntn_79@mail.ru. электрод - электролит. В зависимости от механизма сохранения заряда они бывают двух типов: конденсаторы с двойным электрическим слоем и псевдоконденсаторы [3]. К основным параметрам электрохимического конденсатора относятся рабочий диапазон напряжений и удельная емкость. Рабочее напряжение зависит от типа электролита: для водных электролитов составляет до 1 В, а для органических - до 3 в и выше, однако последние отличаются и более высоким сопротивлением, что увеличивает потери энергии [4]. Удельная емкость данных устройств определяется материалом электрода, морфологией его поверхности, наличием или отсутствием

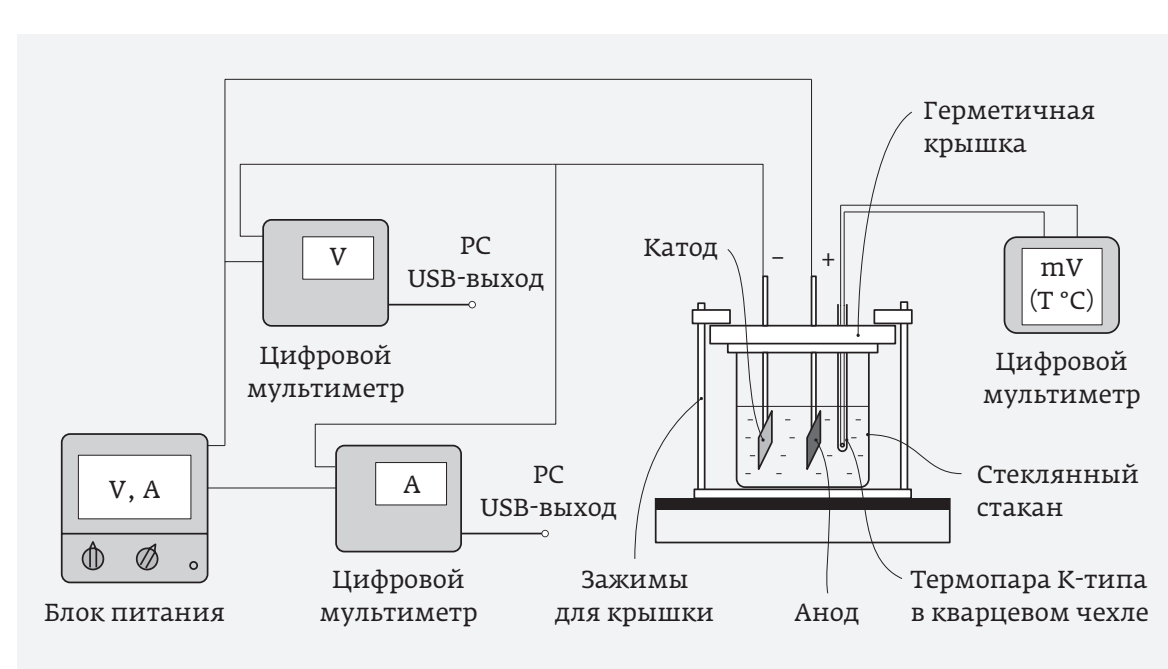

Рис. 1. Установка электрохимического осаждения 


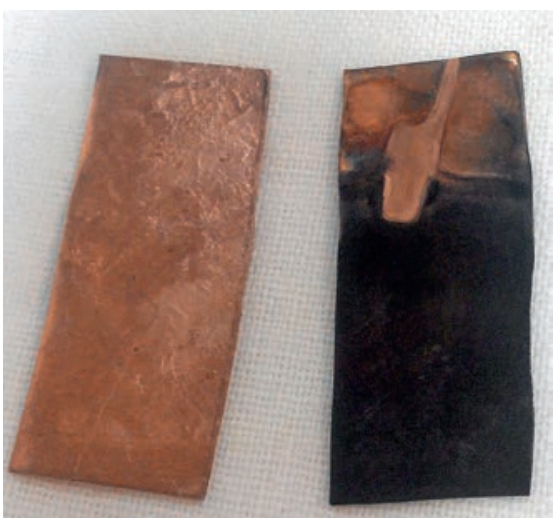

Рис. 2.

Фото структур на медной фольге до и после нанесения кремнийуглеродной пленки

различных функциональных добавок в основной материал. Для изготовления электродов электрохимических конденсаторов широко применяются высокопористые углеродные материалы (активированный уголь, углеродные нанотрубки, графен, оксид графена, мезопористый углерод) [5-7]. Однако значительное удельное сопротивление данных материалов ведет к снижению скорости процессов заряда-разряда и увеличению потерь. Также в качестве материалов для электродов используются пленочные структуры на основе полианилина [8-10] и оксидов переходных металлов [11-13]. Они уступают по удельной площади поверхности углеродным материалам, но отличаются псевдоемкостными свойствами, что позволяет получать электроды с удельной емкостью 0,3 Ф/ см². Углеродные материалы с различными добавками на основе соединений металлов обладают удельной емкостью $\sim 0,715 Ф / \mathrm{CM}^{2}[14]$.

В данной работе исследовались характеристики электродов электрохимических конденсаторов на основе кремний-углеродных пленок, полученных методом электрохимического осаждения из раствора органических соединений. Данный метод прост в реализации, не требует сложного технологического оборудования, что положительно сказывается на экономической составляющей устройств. Также этот метод позволяет получать кремний-углеродные структуры, модифицированные атомами металлов $[15,16]$.

Для проведения экспериментальных работ использовалась установка электрохимического осаждения, показанная на рис. 1. Электролит представлял собой смесь гексаметилдисилазана (ГМдс) с одним из растворителей (этанол, диметилформамид (ДМФА)) в соотношении 1 : 9. Данное соотношение было определено экспериментально исходя из максимальной скорости роста пленок, равной $600-700 \mathrm{HM} / 4$.

В качестве подложек использовалась медная фольга марки М1 толщиной 0,5 мм, которая в процессе осаждения устанавливалась на катод электрохимической ячейки. Начальная плотность тока при осаждении составила 50 мA / см², а затем снижалась из-за увеличения толщины растущей пленки и уменьшения проводимости электролита. Длительность процесса осаждения кремнийуглеродной структуры без металла - 30 мин. Внедрение металла осуществлялось на второй стадии в течение 10 мин при осаждении из раствора электролита с соответствующей солью металла. Процесс осаждения пленок выполнялся в результате диссоциации молекул электролита при высоком напряжении, которые концентрировались у поверхности катода (подложки), частично разлагаясь на атомы, из них и формировалась кремнийуглеродная пленка.

В результате осаждения кремний-углеродной пленки на медную фольгу формируется структура, играющая роль электрода конденсатора и токосъемника. На рис. 2 представлена фотография образца медной фольги с кремнийуглеродной пленкой и без нее.

Полученные образцы электродов из раствора ГМДС и ДМФА с добавлением соли никеля (ДМФА/никель) и из раствора ГМДС и этанола с добавлением соли никеля (этанол / никель) исследовались с помощью циклических вольтамперограмм (ЦВА) и гальваностатических измерений. Исследования проводились с помощью потенциостата-гальваностата P-45Х компании Electrochemical Instruments и трехэлектродной электрохимической ячейки (рис. 3). В качестве электролита использовался 3,5-М раствор $\mathrm{KOH}$.

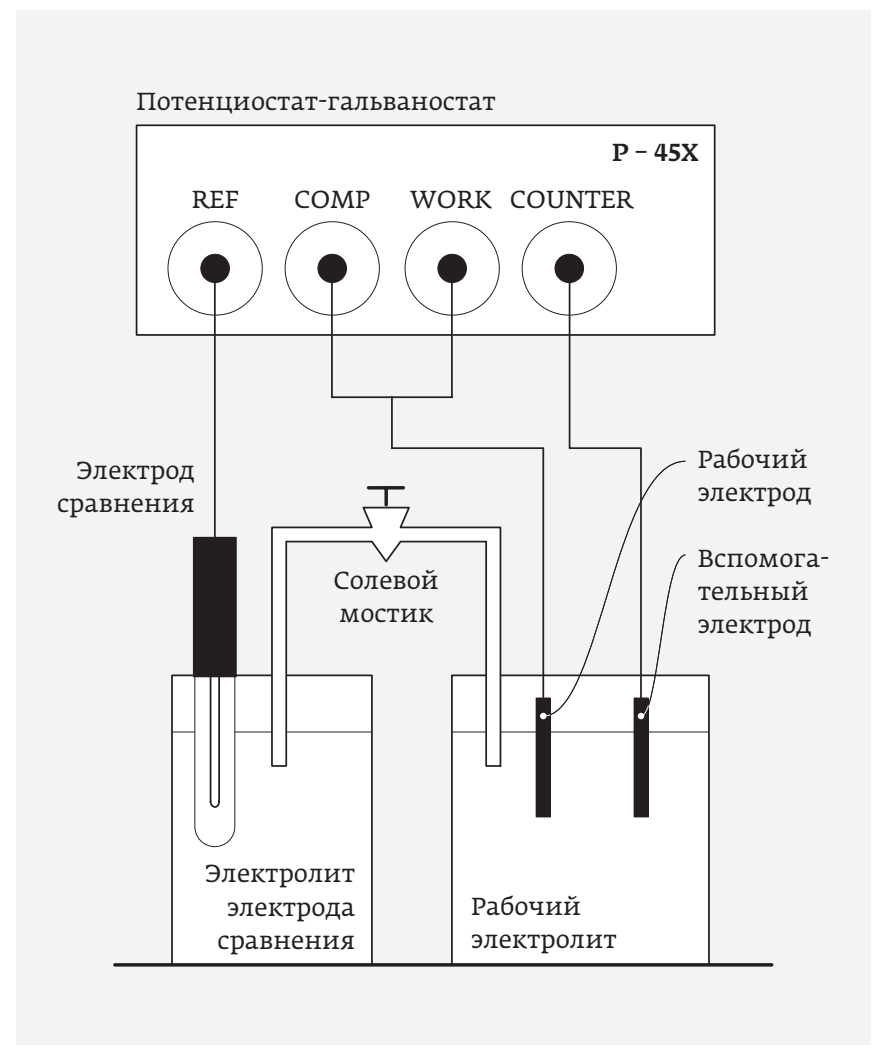

Рис. 3. Трехэлектродная электрохимическая ячейка 


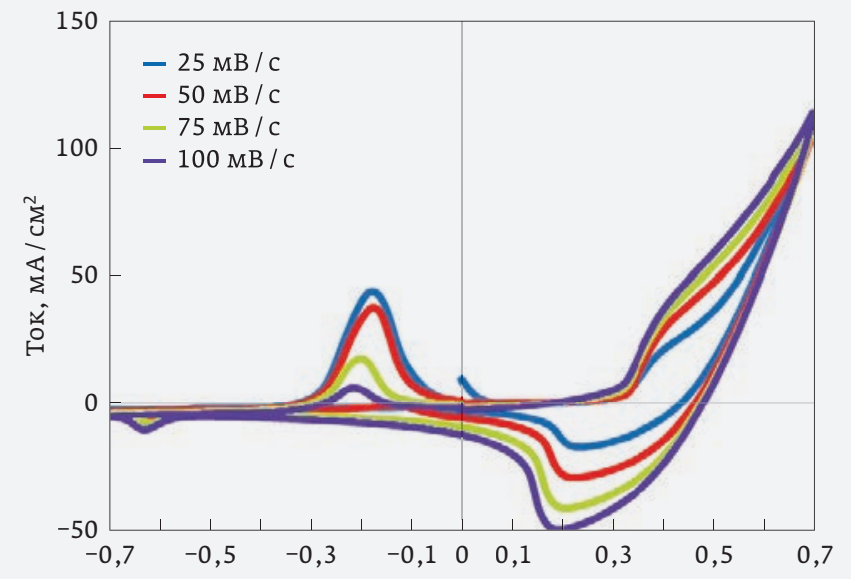

a)

Потенциал, В

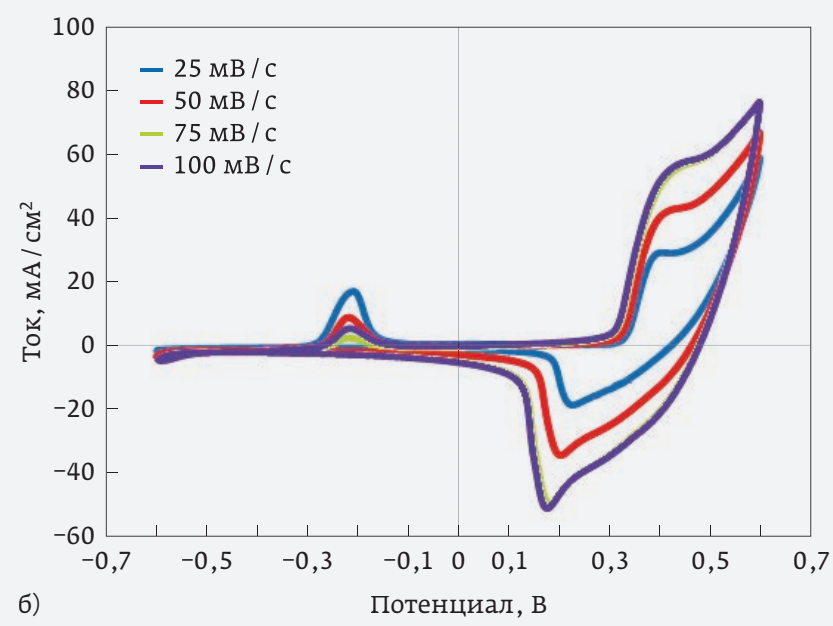

\section{- ДМФА / никель}

где I - плотность тока (мА/ $\left.\mathrm{CM}^{2}\right) ; \varphi$ - потенциал на электроде (В); $t$ - время разряда.

Как видно из табл. 1, максимальная величина удельной емкости образца электрода этанол / никель соответ-



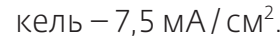

Через изменение потенциала в начальный момент времени разряда ( 0,01 c) было рассчитано внутреннее сопротивление:

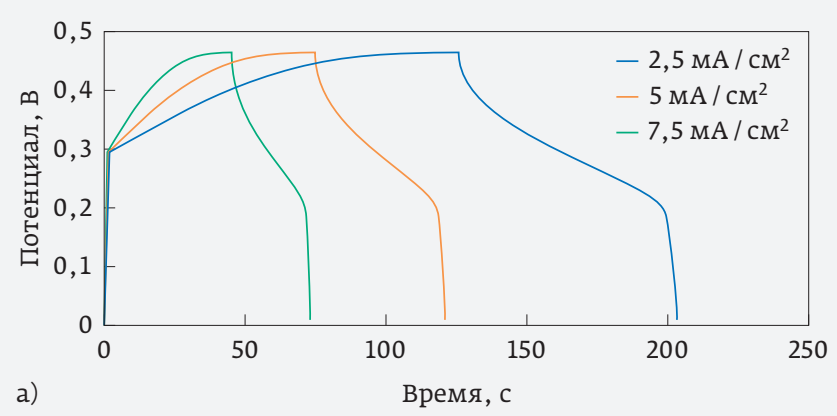

Таблица 1. Значения удельной емкости электродов в зависимости от плотности тока

\begin{tabular}{lll} 
Образец & $\begin{array}{l}\text { Плотность тока, } \\
\text { мА/см }\end{array}$ & $\begin{array}{l}\text { Удельная емкость, } \\
\Phi / \mathrm{cm}^{2}\end{array}$ \\
Этанол/ & 2,5 & 0,74 \\
\cline { 2 - 3 } & 5 & 0,87 \\
\cline { 2 - 3 } & 7,5 & 0,785 \\
\hline ДМФАл & 2,5 & 0,515 \\
\cline { 2 - 3 } & 5 & 0,6 \\
\hline & 7,5 & 0,612 \\
\hline
\end{tabular}

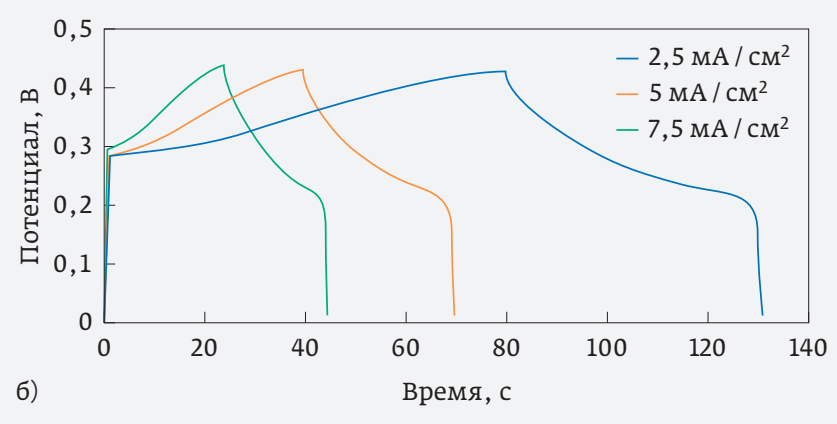

Рис. 5. Гальваностатические измерения образцов электродов: а - этанол / никель; 6 - ДМФА / никель 


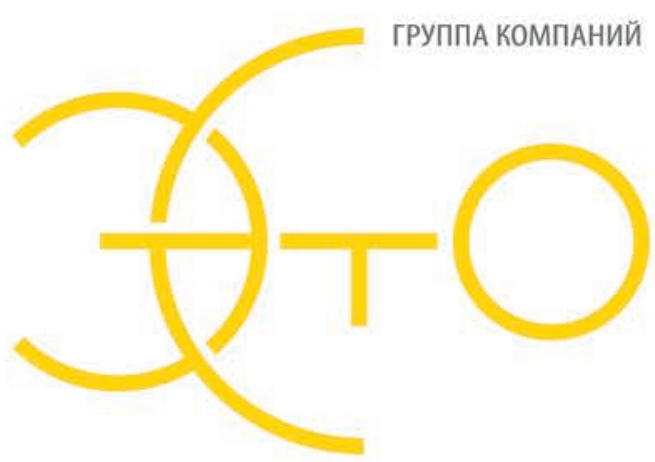

ЭЛЕКТРОННОЕ СПЕЦИАЛЬНОЕ ТЕХНОЛОГИЧЕСКОЕ ОБОРУДОВАНИЕ
Акционерное общество

«Научно-производственное предприятие

«Электронное специальное

технологическое оборудование»
124460 , г. Москва, Зеленоград, Георгиевский проспект, д.5, стр.1 тел.: (499) 729-7751, факс: (499) 479-1239 info@nppesto.ru www.nppesto.ru
«GROOVY ICP» - технология будущего: система критического травления диэлектриков для массовых производств на основе уникального узкозазорного плазмохимического реактора

Разработка A0 «НПП «ЭСТО» при финансовой поддержке Министерства промышленности и торговли Российской Федерации
Минпромторг


Группа компаний ЭСТ0 более 20 лет производит оборудование для микроэлектроники в собственном инженерно-производственном комплексе метражом в 5000 кв.м в г. Зеленограде

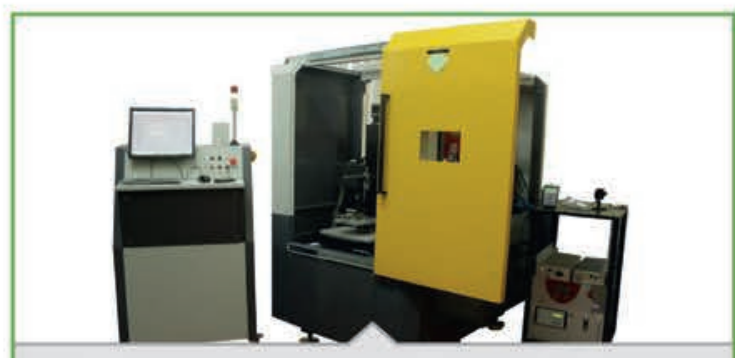

Оборудование для лазерной микрообработки: резка, фрезерование, скрайбирование, прошивка отверстий



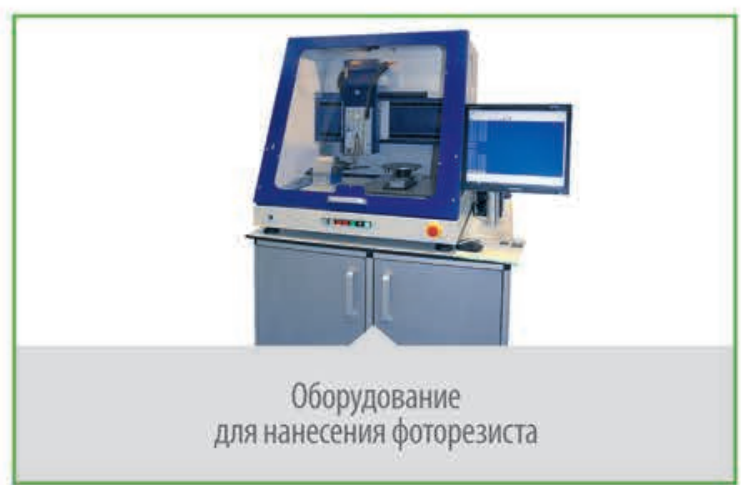

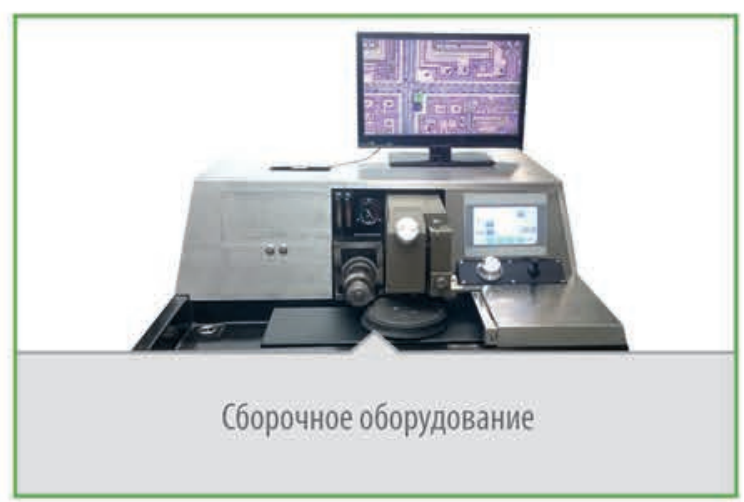


Таблица 2. Характеристики электродов на основе углеродных и кремний-углеродных материалов

\begin{tabular}{|c|c|c|c|c|}
\hline Материал & Удельная емкость, мФ/см² & Электролит & Окно потенциалов, В & Литература \\
\hline VN/YHT & 178,5 & $\mathrm{H}_{3} \mathrm{PO}_{4} /$ гель & $-0,1-0,4$ & [17] \\
\hline Композит на основе VN/УНT & 715 & $\mathrm{Na}_{2} \mathrm{SO}_{4} /$ гель & $-0,1-0,2$ & [14] \\
\hline КУП: N & 8,5 & $3,5-\mathrm{M} \mathrm{KCl}$ & $0-1$ & [18] \\
\hline $\mathrm{SiC}$ нановолокна & 0,24 & $3,5-\mathrm{M} \mathrm{KCl}$ & $-0,2-0,6$ & [19] \\
\hline 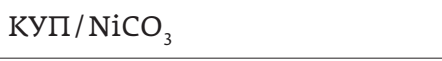 & $612 ; 785$ & \multirow{2}{*}{$3,5-\mathrm{M} \mathrm{KOH}$} & \multirow{2}{*}{$0-0,5 \mathrm{~B}$} & \multirow{2}{*}{$\begin{array}{c}\text { Данная } \\
\text { работа }\end{array}$} \\
\hline КУП & 303 & & & \\
\hline
\end{tabular}

$$
\operatorname{ESR}=\frac{\Delta \varphi}{I}
$$

где $\Delta \varphi$ - изменение потенциала (В); I - абсолютный ток разряда (A) [20]

Для образцов электродов этанол / никель и ДМФА / никель величина внутреннего сопротивления составила 1,6 и 1,28 Ом соответственно.

Наряду с этим исследовалась стабильность удельной емкости данных образцов электродов при 2000 циклов заряда-разряда. Результаты исследований стабильности представлены на рис. 6.

Как показало сравнение характеристик разработанных электродов с параметрами электродов на основе углеродных структур и кремний-углеродныхпленок, представленных в литературе (табл. 2), предложенные авторами электроды - весьма перспективные, по рабочим характеристикам превосходят известные на настоящий момент.

Удельная емкость образцов электродов этанол/никель и ДМФА / никель после 2000 циклов заряда-разряда снизилась на 6,2 и 5,8\% соответственно, что говорит

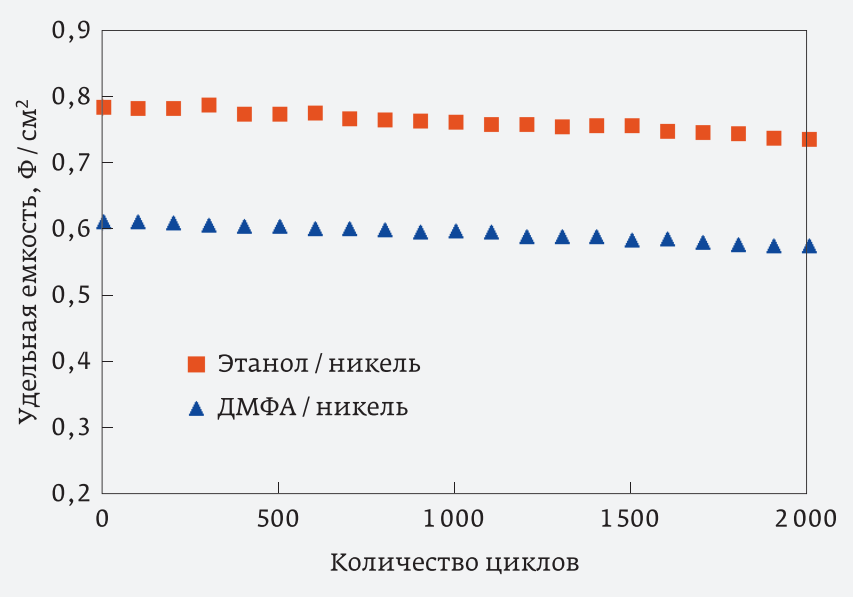

Рис. 6. Стабильность удельной емкости образцов этанол / никель, ДМФА / никель о высоком уровне стабильности емкостных параметров данных электродов.

Таким образом, разработанный техпроцесс в силу технологической простоты и низкой себестоимости может быть применен для создания электродов в мелко- и крупносерийных масштабах. Полученные в соответствии с разработанным технологическим процессом экспериментальные образцы электродов электрохимических конденсаторов на основе кремний-углеродных структур, модифицированных марганцем и никелем, имеют следующие параметры: величина внутреннего сопротивления 1,28-1,9 ОМ, величина удельной емкости до 0,87 Ф/ см², падение удельной емкости после 2000 циклов зарядаразряда при плотности тока 7,5 мА/см²-6,2\%. Указанные значения параметров свидетельствуют о высокой перспективности использования кремний-углеродных структур для создания электродов электрохимических конденсаторов и об актуальности дальнейших исследований в этом направлении.

\section{ЛИТЕРАТУРА}

1. Суперконденсаторы для Raspberry Pi // Журнал "Хакер». http: xakep.ru/supercapacitor-rpi/.

2. Conway B.E. Electrochemical Supercapacitors: Scientific Fundamentalsand Technological Applications. // New York Kluwer Academic / Plenum Publishing, 1999, P. 698-703.

3. Conway B. E. Transition from Supercapacitor to Battery Behavior in Electrochemical Energy Storage // J. Electrochem. Soc., 1991, V. 138. No. 6, P. 1539-1544.

4. Вольфкович Ю. М., Сердюк т. М. Электрохимические конденсаторы // Электрохимическая энергетика, 2001, T. 1, № 3. C. 14-28.

5. Ehsani A., Shiri H. M., Kowsari E., Safari R., Shayeh J. S., Barbary M. J. Colloid Interfacesci., 490 (2017) 695.

6. Candelaria S. L. Nanostructured carbon for energy storage and conversion // Nano Energy, 2012, Vol. 1. P. 195-200.

7. Li J., X. Cheng X., Shashurin A., Keidar M. Review of Electrochemical Capacitors Based on Carbon Nanotubes and Graphene. // Graphene, 2012, Vol. 1. P. 1-13.

8. Моисеева Т.А., Мясоедова Т.Н. Исследование элек- 


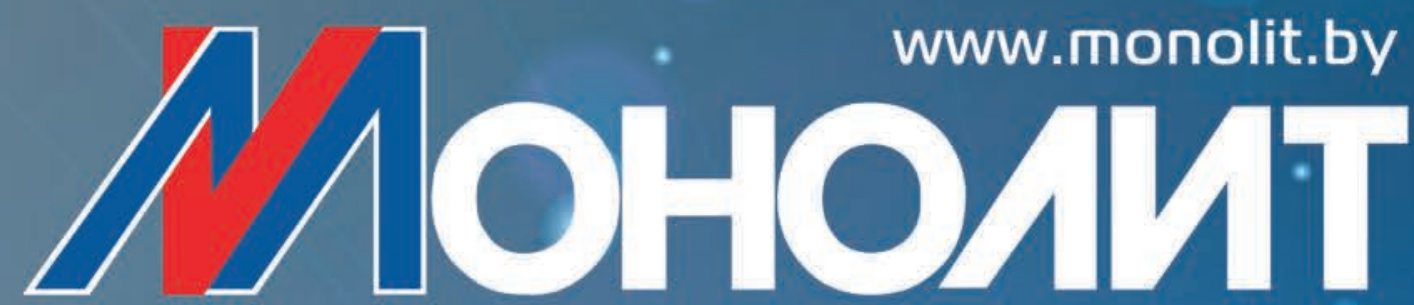

\section{МНОГОСАОЙНЫЕ КЕРАМИЧЕСКИЕ КОНАЕНСАТОРЫ}

\section{ИМПОРТОЗАМЕШАЮШАЯ ПРОАУКШИЯ}

м^я высоконацёжной аппаратуры

-

ТЕРМОРЕЗИСТОРЫ

с положительным температурным

коэффишиентом сопротивления

РЕГИСТРЫ

НАГРЕВАТЕАЬНЫЕ

210101, РЕСПУБЛИКА БЕ АРРУСЬ

г. Витебск, ул. М. Горыкого, 145

ОтАел маркетинга:

тел.: + 375 (212) 36-44-52

факс: + 375 (212) 36-44-53

e-mail: monolmarket@mail.ru

ОтАел продаж: тел:

+ 375 (212) 36-45-34

факс: + 375 (212) 36-44-65

e-mail: monosbet@mail.ru 
трохимических характеристик композитных материалов на основе полианилина // Известия ЮФу. Технические науки, 2015, № 12. С. 123-131.

9. Hu C., Chu C. Electrochemical and textural characterization of iridium-dopedpolyaniline films for electrochemical capacitors. Mater. Chem. Phys. 651. (2000) 329-338.

10. Dhawale D., Vinu A., Lokhande C. Stable nanostructured polyaniline electrode for supercapacitor application // Electrochim. Acta., 56 (2011) 9482-9487.

11. Jiang Y., Chen D., Song J., Jiao Z., Ma Q., Zhang H., Cheng L., Zhao B., Chu Y. A facilehydrothermal synthesis of graphene porous $\mathrm{NiO}$ nanocomposite and its application inelectrochemical capacitors // Electrochim. Acta., 91 (2013) 173-178.

12. Wang D., Yu Y., He H., Wang J., Zhao W., Abruna H. Template synthesis of hollowstructured $\mathrm{CO}_{3} \mathrm{O}_{4}$ nanoparticles as high-performance anodes for lithium-ion batteries. // ACS Nano 9 (2015) 1775-1781.

13. Wang X., Huang W., Sebastian P. J., Gamboa S. Sol-gel template synthesis of highly ordered $\mathrm{MnO}_{2}$ anowire arrays // J. Power Sources, 140 (2005) 211-215

14. Zhang Q., Wang X., Pan Z. et al. Wrapping aligned carbon nanotube coaxial composite sheets around vanadium nitride nanowire arrays for asymmetric coaxial fiber-shaped supercapacitors with ultrahigh energy density // Nano Lett., 2017, Vol. 17, Iss 4, P. 2719-2726.

15. Grigoryev M.N., Myasoedova T.N., Mikhailova T.S. The electrochemical deposition of silicon-carbon thin films from organic solution // Journal of Physics: Conference Series, 2018, Voc. 1124, № 8, P. 081043.

16. Григорьев М.Н., Михайлова Т.С., Мясоедова Т.Н. Получение кремний-углеродных пленок на электропроводящей и диэлектрических подложках методом электрохимического осаждения // Известия ЮФУ. Технические науки, 2018, № 7. С. 56-66.

17. Xiao X., Peng X., Jin H. et al. Freestanding mesoporous VN/CNT hybrid electrodes for flexible all-solidstatesupercapacitors // Adv. Mater., 2013, Vol. 25, Iss 36 P. 5091-5097

18. Yu G.H., Xie X., Pan L.J. et al. Hybrid nanostructured materials for high-performance electrochemical capacitors // Nano Energy, 2013, Vol. 2, № 2. P. 213-234.

19. Zhao Y., Kang W., Li L. et al. Solution Blown Silicon Carbide Porous Nanofiber Membrane as Electrode Materials // Electrochimica Acta., 2016. P. 1-28.

20. Панкрашкин А. Ионисторы Panasonic: физика, принцип работы, параметры // Компоненты и технологии, 2006. № 3. С. 12-17.

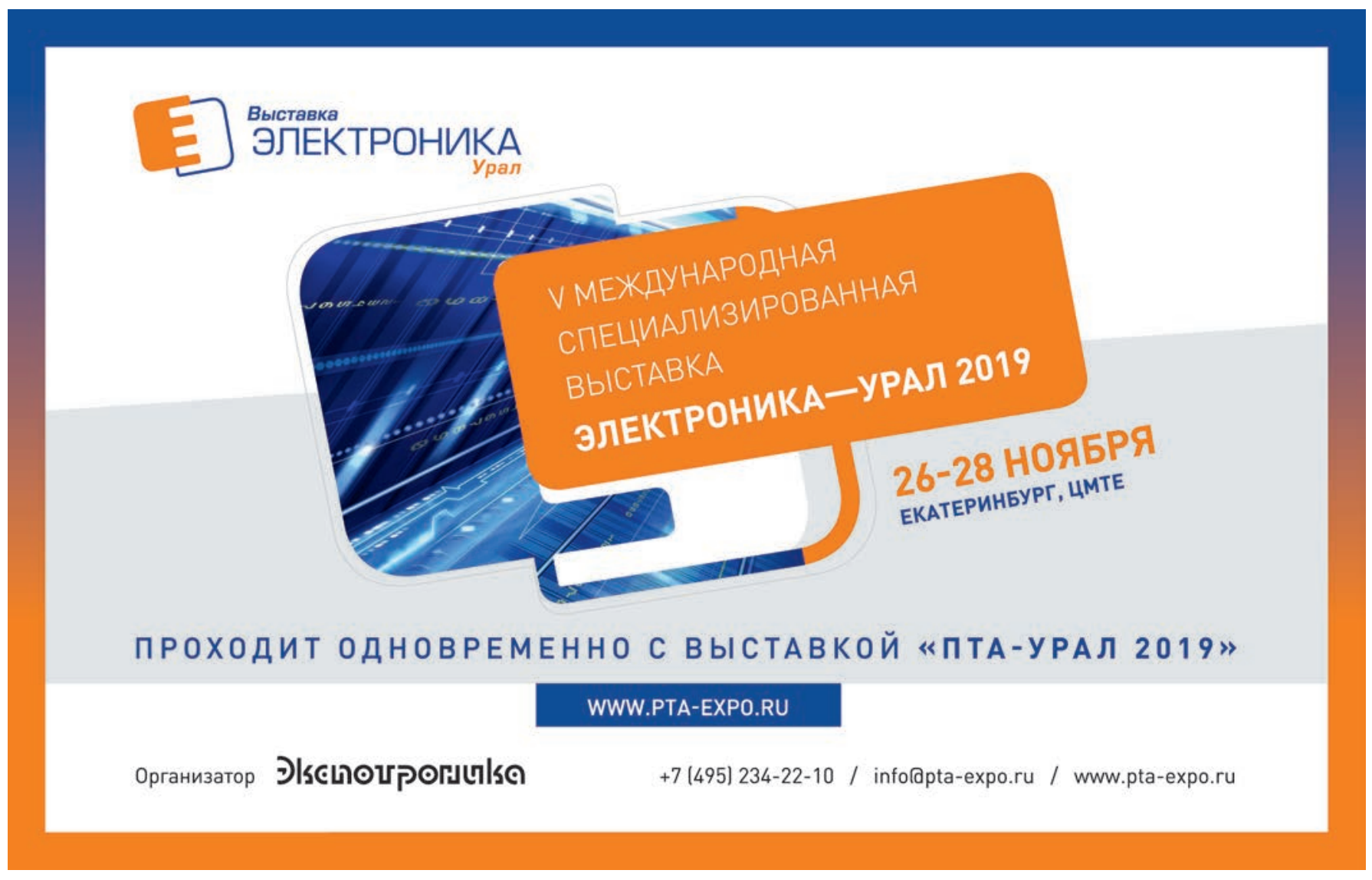

